\title{
REASSESSING THE CONCEPTUAL-PROCEDURAL DISTINCTION
}

\author{
Deirdre Wilson
}

To appear in Lingua 2016. Published online at http://dx.doi.org/10.1016/j.lingua.2015.12.005

\begin{abstract}
My aim in this paper is to reassess the conceptual-procedural distinction as drawn in relevance theory in the light of almost thirty years of research. In section 1, I make some comparisons between approaches to semantics based on a conceptual-procedural distinction and those based on a distinction between truth conditions and conditions for appropriate use. In section 2, I present a brief history of the conceptual-procedural distinction as drawn in relevance theory. In section 3, I consider the nature of procedural encoding and discuss whether it is best seen as semantic or pragmatic. In section 4, I outline some parallels and differences between procedural and use-conditional accounts of interjections. In section 5, I discuss the implications of the conceptual-procedural distinction for lexical pragmatics and consider some recent proposals about how it might be extended. In section 6, I reassess the conceptual-procedural distinction in the light of current evolutionary approaches to cognition and point out some future directions for research.
\end{abstract}

Keywords: Discourse connectives; Interjections; Grammaticalization; Lexical Pragmatics, Modularity

\section{Highlights}

- Comparing procedural and use-conditional approaches to semantics

- Considering whether procedural meaning is best seen as semantic or pragmatic

- Assessing the truth-conditional status of conceptual and procedural meaning

- Considering some possible extensions to current accounts of procedural meaning

- Reassessing procedural meaning in the light of evolutionary accounts of cognition

\section{Introduction}

Diane Blakemore began her book Semantic Constraints on Relevance (1987) by arguing that Gazdar's famous slogan "Pragmatics = Meaning minus Truth Conditions" (Gazdar, 1979:2) lays an inadequate foundation for a cognitively plausible pragmatic theory. Her main concern was a class of inferential connectives such as but, so and moreover which are widely seen as non-truth-conditional: she argued that these should fall within the scope of linguistic semantics rather than pragmatics, since their meanings are linguistically encoded rather than pragmatically inferred. Blakemore's analyses of these connectives differed substantially from those traditionally offered for regular 'content' words like scarlet, hop and giraffe. Rather 
than encoding concepts, constituents of a conceptual representation system or 'language of thought', she argued that the information they encode is essentially procedural: they indicate the inferential processes addressees are expected to use in identifying the speaker's meaning (i.e. the array of propositions that the speaker overtly intended to make manifest or more manifest, cf. Sperber and Wilson, 2015). In her view, the differences between these connectives and regular 'content' words are enough to suggest a "non-unitary theory of linguistic semantics":

On the one hand, there is the essentially conceptual theory that deals with the way in which elements of linguistic structure map onto concepts - that is, onto constituents of propositional representations that undergo computations. On the other, there is the essentially procedural theory that deals with the way in which elements of linguistic structure map directly onto computations themselves - that is, onto mental processes. (Blakemore, 1987:144)

Blakemore's procedural approach has since been extended to a variety of further expressions which present problems for the traditional view that the meaning of a word is the concept it encodes, including indexicals, mood indicators, discourse particles, interjections and pejoratives, and its implications are still being explored. ${ }^{1}$

Blakemore's concerns in Semantic Constraints on Relevance were explicitly cognitive: her aim was to contribute to a "psychologically plausible account of the role of context in utterance interpretation" (Blakemore, 1987:1). On the formal side, researchers in a tradition inspired by David Kaplan $(1989,1999)$ also reject Gazdar's slogan and draw the borderline between linguistic semantics and pragmatics in a similar way to Blakemore's (e.g. Potts, 2005, 2007; Gutzmann, 2015). Kaplan (2004:3) describes his reasons for moving beyond the traditional concerns of truth-conditional semantics in the following terms:

I began to see the semantics of indexicals as having greater affinities with the semantics (or potential semantics) of epithets, diminutives, interjections, nicknames, ethnic slur terms, and the like, than with the paradigms of meaningfulness, things like fortnight and feral and so on.

However, where Blakemore analyses these expressions in procedural terms and sees them as evidence for a "non-unitary theory of semantics", Kaplan analyses them in terms of felicity conditions, or conditions for their appropriate use, and aims to provide a unitary account of what he calls a "Semantics of Meaning" and a "Semantics of Use": ${ }^{2}$

I now believe that by attending to rules of use - the right sort of rules of use - we can extend our formal semantics, and thus even our logic, to systematically account for the

\footnotetext{
${ }^{1}$ For a recent collection on procedural meaning, see Escandell-Vidal et al. (2011).

${ }^{2}$ For a recent collection on use-conditional semantics, see Gutzmann and Gärtner (2013).
} 
ignored semantic phenomena, and with surprising and, I hope, illuminating results. (Kaplan, 2004:3)

As far as I know, despite the obvious overlaps in the range of data they are dealing with, there have been no attempts to compare the two approaches in any systematic way. ${ }^{3}$ This is partly because of a difference in their priorities. Use theorists generally approach the data from the direction of formal semantics and are primarily concerned with issues of truth and validity, whereas procedural semanticists (typically relevance theorists) generally have a background in pragmatics and are primarily concerned with how language provides inputs to a cognitively plausible comprehension mechanism. Researchers in both frameworks have produced a wealth of subtle observations, but have also encountered a variety of problems that are still awaiting solutions. This raises the question of how they might benefit from each other's results. Are the two frameworks compatible? Are some data best analysed in procedural terms and others in use-conditional terms? Can procedural analyses be straightforwardly translated into use-conditional analyses and vice versa? To the extent that the two frameworks are compatible and their results are inter-translatable, this raises the further question of whether they are genuinely distinct.

I think these questions are worth raising, and although I will not offer any systematic answers, I will comment on them where possible along the way. However, my main aim in this paper is to reassess the conceptual-procedural distinction as it has been drawn in relevance theory in the light of almost thirty years of research, considering some common objections and problems and speculating on how it might be extended in future work. ${ }^{4}$ The paper is organised as follows. In section 2, I look briefly at how the conceptual-procedural distinction was introduced into relevance theory. In section 3, I discuss the nature of procedural encoding. In section 4, I consider some parallels and differences between procedural and use-conditional accounts of interjections. In section 5, I discuss the implications of the conceptual-procedural distinction for lexical pragmatics and reflect on some recent speculative proposals about how it might be extended. In section 6, I discuss the relation between the conceptual-procedural distinction and current evolutionary approaches to cognition such as the 'massive modularity' hypothesis. Section 7 is a brief conclusion.

\section{The conceptual-procedural distinction in relevance theory}

At the heart of Diane Blakemore's procedural approach to semantics is the idea that in a pragmatic framework such as relevance theory, where utterance comprehension involves not only identifying the proposition expressed but exploring the cognitive effects achieved by processing it in the context of an appropriately selected set of assumptions, it would be useful to have some linguistic devices whose function is to constrain the inferential comprehension process and guide the hearer towards the appropriate contextual assumptions and cognitive

\footnotetext{
${ }^{3}$ For some preliminary comparisons, see Blakemore (2011, 2015); Wharton (this issue).

${ }^{4}$ For a preliminary reassessment, see Wilson (2011). I have extended the arguments of that paper, addressing different issues and examples where possible in order to keep any overlap to a minimum.
} 
effects. Blakemore's proposal was to treat inferential connectives such as but, so and moreover as devices of this type:

The goal of this study is to show that the meanings of those expressions that do not play a role in determining the proposition expressed by the utterances that contain them should be analysed in terms of constraints on the inferential computations the hearer performs in order to establish the impact of that proposition - or, in other words, its relevance. (Blakemore, 1987:18)

In this framework, non-truth-conditional connectives are seen as procedural in the sense that they encode "instructions" to the hearer on how to find the intended relevance of the proposition expressed. Approaches of this type can be traced back to Frege (1892/1993:38), who saw but and still as devices for "aiding the hearer's understanding" without affecting the propositional content or thought expressed. ${ }^{5}$

To illustrate, consider (1a)-(1c):

(1) a. Lisa is French, so she doesn't need a passport to travel to Germany.

b. Joe's argument is unoriginal. Moreover, it's invalid.

c. The sun is shining, but there are clouds on the horizon.

In (1a), the inferential use of $s o$ can be analysed as indicating that the proposition that Lisa doesn't need a passport to travel to Germany is a conclusion derivable from the proposition that she is French (together with background assumptions) (Blakemore, 1987:85-90). In (1b), the inferential use of moreover can be analysed as indicating that the propositions expressed by the preceding and following clauses provide evidence for a common conclusion in a context available to the addressee (Blakemore, 1987:91-97); and in (1c), the 'denial of expectation' use of but can be analysed as indicating that the proposition expressed by the following clause should be understood as inhibiting a conclusion potentially derivable from the first clause (Blakemore, 1987:125-41; Hall, 2007). This procedural approach has been used to analyse a wide variety of inferential connectives in different languages (e.g. Blass, 1990; Gutt, 1991; Unger, 2011).

Blakemore's initial analyses suggested that the conceptual-procedural distinction coincides with the distinction between truth-conditional and non-truth-conditional meaning (where truth-conditional meaning contributes to the proposition expressed by an utterance, and hence to its speech-act content, and non-truth-conditional meaning constrains the inferential phase of comprehension). In a second phase of research, it became clear that the two distinctions cross-cut each other in several ways. For instance, Wilson and Sperber (1993) argued that (a) not all conceptual expressions are truth-conditional, (b) not all procedural expressions are

\footnotetext{
${ }^{5}$ Horn (2007) draws interesting parallels between Frege's insights and current approaches to pragmatics.
} 
non-truth-conditional, and (c) not all procedural expressions impose constraints on the construction of contexts and cognitive effects.

As evidence that not all non-truth-conditional expressions are procedural, consider the illocutionary and attitudinal adverbials frankly and unfortunately. These are generally treated as non-truth-conditional on the ground that they modify the illocutionary force of an utterance rather than contributing to the content of the speech act performed. Thus, the speaker of (2) is naturally understood as asserting that Joe's argument is incoherent, and indicating by the use of the illocutionary adverbial that she is speaking frankly:

Frankly, Joe's argument is incoherent.

However, rather than treating frankly in (2) as procedural because of its non-truth-conditional nature, Wilson and Sperber (1993) note that it has a synonymous manner-adverbial counterpart which is a regular 'content' word and contributes to truth conditional content in the regular way, as in (3):

(3) Sue told Joe frankly that his argument was incoherent.

They propose that both uses of frankly are best seen as encoding concepts, which (in different environments) can contribute either to the proposition expressed by the utterance or to its socalled 'higher-order explicatures', which carry information about the speaker's propositional or affective attitude or the type of speech act she intends to perform. ${ }^{6}$ On this approach, the speaker of (2) would communicate a basic-level explicature that Joe's argument is incoherent and a higher-order explicature that she is being frank in telling him so. The truth conditions of the assertion would depend on the basic explicature, while the higher-order explicature would make no difference to the truth-conditional content of the utterance (although it would have truth conditions of its own). Thus, frankly in (2) is both conceptual and non-truthconditional.

The pronouns we and you, or the demonstratives this and that, illustrate a second way in which the conceptual-procedural distinction and the truth-conditional/ non-truth-conditional distinction come apart. Pronouns and demonstratives are not plausibly analysed as encoding full concepts, since their referents vary from context to context and have to be pragmatically inferred. However, they do contribute to the truth-conditional content of utterances, since they affect the pragmatic process of reference resolution. Wilson and Sperber (1993) propose to treat them as encoding procedural constraints on the proposition expressed by the utterance rather than the intended context and cognitive effects. On this approach, use of the pronoun we in (4) would restrict the search space for reference resolution to sets consisting of the speaker and some other individual(s):

\footnotetext{
${ }^{6}$ On higher-order explicatures, see Sperber and Wilson (1986/995:243-254; 1988); Ifantidou (2001); Wilson (2000); Carston (2002); Jodlowiec (2015).
} 
Thus, we in (4) is both procedural and truth-conditional (see e.g. Powell, 2010; Scott, 2011, 2013 , this issue).

Finally, a variety of non-truth-conditional items such as mood indicators, sentence and discourse particles, interjections and prosody have been analysed as encoding a still further type of procedural constraint, this time on the construction of higher-order explicatures. For instance, the addition of an interrogative particle, question intonation or interrogative word order to the utterance in (5) might encourage construction of the higher-order explicature in (6a); use of the interjection phew! or certain types of affective intonation with (5) might encourage construction of the higher-order explicature in (6b); and addition of a warning tone of voice might encourage construction of the higher-order explicature in (6c) (see e.g. Wilson and Sperber, 1993); Escandell-Vidal, 2002; Jary, 2011):

(5) Lisa is going on holiday.

(6) a. The speaker is wondering whether Lisa is going on holiday.

b. The speaker is expressing relief that Lisa is going on holiday.

c. The speaker is warning the addressee that Lisa is going on holiday.

I will discuss some of these analyses in later sections.

While there is broad agreement among use-conditional theorists and procedural theorists on which constructions call for a new approach to semantics, there is less consensus on two types of case: appositive relatives and parentheticals, on the one hand, and connectives such as but and so, on the other. Relevance theorists treat parentheticals and appositives as both conceptual and truth-conditional - conceptual for parallel reasons to those given above for illocutionary and attitudinal adverbials, and truth-conditional on the ground that their falsity leads to falsity of the utterance as a whole (Blakemore, 1993; Ifantidou, 2001). Some use theorists, by contrast, treat them as non-truth-conditional and analyse them as carrying Gricean conventional implicatures (e.g. Potts, 2005). However, as Horn (2007:52) points out, the fact that appositives and parentheticals may contain overt performatives, as in (7), is incompatible with the view that their content is merely implicated, and confirms their truthconditional status.

This administration's policy on Iraq, which I hereby endorse, is morally bankrupt.

There has also been some debate about the non-truth-conditional status of connectives such as but and so. For instance, Bach (1999) argues that $P$ but $Q$ expresses the proposition that $\mathrm{P}$ contrasts with $\mathrm{Q}$, which in his view contributes to the truth-conditional content of the utterance although it is often not salient enough to affect truth-value judgements. Hall (2007) discusses several problems with this proposal. Consider (8), for instance:

It's raining but the ground is wet. 
As Hall points out, the contribution of but should be highly salient here, yet in a situation where it is raining and the ground is indeed wet, (8) would be judged true (though infelicitous) despite the lack of any contrast. Further evidence for the non-truth-conditional status of but comes from standard embedding tests. Consider (9a)-(9b):

(9) a. If the sun is shining but there are clouds on the horizon, you should cancel your picnic.

b. If the sun is shining and there are clouds on the horizon, you should cancel your picnic.

In both utterances, the speaker is naturally understood as encouraging the addressee to cancel the picnic on the following two conditions: (a) the sun is shining, and (b) there are clouds on the horizon. The fact (if it is a fact) that these conditions are in contrast, or that (b) is unexpected in the light of (a), does not affect the truth conditions of either (9a) or (9b). This suggests that the additional information carried by but is purely non-truth-conditional. Parallel arguments apply to moreover in (10a) as compared with its absence in (10b):

(10) a. If Joe's argument is unoriginal and moreover it's invalid, you should reject his paper.

b. If Joe's argument is unoriginal and invalid, you should reject his paper.

The fact that (10a) and (10b) are true and false together strongly suggests that the information carried by moreover is non-truth-conditional.

The case of connectives such as so and therefore is more complex, since they sometimes seem to be truth-conditional and sometimes not. Grice (1989:120-121) famously saw so and therefore as non-truth-conditional and analysed them as carrying conventional implicatures. In some cases, their non-truth-conditional status appears to be confirmed by standard embedding tests. Consider (11a)-(11c):

(11) a. If Lisa is French and therefore a citizen of the European Union, she can travel to Germany without a passport.

b. If Lisa is French and so a citizen of the European Union, she can travel to Germany without a passport

c. If Lisa is French and a citizen of the European Union, she can travel to Germany without a passport.

In each case, the speaker is naturally understood as claiming that Lisa can travel to Germany without a passport on the following two conditions: (a) she is French and (b) she is a citizen of the European Union. The fact that (b) follows from (a) (together with background information) seems to have no more impact on the truth conditions of (11a)-(11c) than did the contrastive information carried by but in (9a)-(9b) above. In this case, so and therefore seems to be clearly non-truth-conditional. 
With other examples, though, the standard embedding tests seem to show that so and therefore are clearly truth-conditional. Consider (12a)-(12c):

(12) a. If the council fails to repair a pothole and you therefore break your leg, you should sue.

b. If the council fails to repair a pothole and so you break your leg, you should sue.

c. If the council fails to repair a pothole and you break your leg, you should sue.

In each case, the speaker is naturally understood as encouraging the addressee to sue in the following three conditions: (a) the council fails to repair a pothole, (b) he breaks his leg, and (c) he broke his leg as a consequence of the council's failure to repair the pothole. ${ }^{7}$ Intuitions are fairly clear in both (11) and (12), and an adequate account of therefore and so (and of similar connectives such as hence, thus and then) should shed light on why they sometimes seem to contribute to truth-conditional content and at other times not. I will suggest a possible procedural explanation later in the paper. In a framework that distinguishes use conditions from truth conditions, it might be more difficult to provide a unitary account, since some uses of these connectives would have to be dealt with in a 'Theory of Meaning' and others within a 'Theory of Use'.

Apart from some debate about its truth-conditional status, there is a further difference between use-conditional and procedural theorists in their analyses of but. Frege, Grice and most use-conditional theorists analyse $P$ but $Q$ as indicating that $P$ and $Q$ contrast in some way, whereas relevance theorists tend to follow the lead of Anscombre and Ducrot (1977:28), who treat the 'denial of expectation' use as basic and propose the following analysis:

In $P$ but $Q, P$ implies not-R; $Q$ implies $R ; Q$ has more weight.

Alison Hall (2007:168), who surveys a wide range of analyses of but - some truthconditional and others non-truth-conditional, some conceptual and others procedural - ends by advocating a non-truth-conditional procedural account on which "but indicates that what follows is cutting off a line of inference opened up by the previous clause." It is worth noting that whereas contrastive analyses of but seem to be fairly easily presentable in either procedural or use-conditional terms, it is harder to see what the use-conditional counterpart to Hall's procedural analysis might be. How would the felicity conditions on the 'denial of expectation' use of but be formulated? For several reasons, then, but and other inferential connectives present a certain challenge to the use-conditional approach.

\section{What is procedural encoding?}

\footnotetext{
${ }^{7}$ Examples such as (12c) are standardly used to show that pragmatic enrichment can contribute to the truth-conditional content of utterances (e.g. Carston, 2002).
} 
As noted above, relevance theorists often describe procedural expressions as "instructing" the hearer to perform certain computations. Anne Bezuidenhout (2004) makes some suggestions about how this description should be understood. She considers two hypotheses. On the first, the "instructions" associated with a given procedural expression would be couched in a "proprietary code for representing semantic information" and realised as rules in the lexical entry for that expression specifying that if a certain condition is met, then a certain action must be performed. Comprehension would then proceed as follows:

When the speaker-hearer accesses an item in the lexicon, he or she is able to access the information associated with that item, presumably in some sort of 'look-up' process that allows the entry for that item to be searched for relevant information. If the item encodes procedural information, the look-up process will access a rule. If the item encodes conceptual/descriptive information, the look-up process will access a concept. (Bezuidenhout 2004:7).

Suppose, now, that the "proprietary code" in which the rules are couched is Mentalese (i.e. a conceptual representation system or 'language of thought'), and that the actions specified by the rules involve manipulation of Mentalese representations. Then the result would be an infinite regress of the type made familiar by Dennett (1981) and Kripke (1982):

If procedural rules are treated as items that are represented in Mentalese and as items that are listed in lexical entries (which in turn are simply lists of representations - data structures - that can be searched), then we face a form of the rule following paradox. Rules themselves will simply be more symbols along with the symbols they are meant to manipulate. But then it looks as though we'll have to posit another set of rules for instructing us on how to use the original rules. Now, if these new rules are themselves items that are represented in Mentalese, the same problem arises all over again. Clearly we are off on an infinite regress here. (Bezuidenhout 2004:8)

To stop the regress, we must assume that "at some point rules give way to procedures, where procedures are understood in some non-representational or non-symbolic way" (Bezuidenhout 2004:8).

The second hypothesis Bezuidenhout considers, then, is that the procedures associated with non-truth-conditional expressions are of this non-representational, non-symbolic type. Bezuidenhout goes on to propose that these procedures should be analysed in dispositional terms, and seen as embodied in the causal architecture of the language production and comprehension system: that is, as part of the system of linguistic performance rather than linguistic competence. She concludes that whereas the conceptual information encoded by linguistic expressions is correctly described as semantic, procedural information of the type discussed by relevance theorists is better seen as pragmatic:

The conceptual meanings that are associated with lexical items constitute an ideal speaker-hearer's semantic competence, whereas the ability to use those concepts 
constitutes the ideal speaker-hearer's procedural knowledge, and this procedural knowledge is what drives language production and understanding (viz. linguistic performance)... The notion of a procedural unit is something that has a place in an account of language use, and hence it belongs to a theory of pragmatic performance and not to a theory of semantic competence. (Bezuidenhout 2004:13)

Bezuidenhout is right to point out that the nature of the procedural information encoded by lexical items has been insufficiently addressed in relevance theory, and that these procedures must ultimately be seen as dispositional and analysed as part of the causal structure of the cognitive system. However, it does not seem to me to follow that procedural information of the type that relevance theorists have discussed is pragmatic rather than semantic, or that it differs in this respect from conceptual information.

As noted above, the distinction between linguistic semantics and pragmatics is generally seen as coinciding with the distinction between decoding and inference (Ariel, 2010). To say that a particular expression in a public language (e.g. French) encodes a certain concept or procedure is to say that the internalised grammar and lexicon of that language interface with the rest of the cognitive system in such a way that activating that expression systematically activates the associated concept or procedure, and vice versa. On this approach, acquiring a public language involves setting up the interface between the linguistic system and the rest of the cognitive system in an appropriate way: so, for instance, learning a 'content' word such as scarlet or hop involves establishing a link between a new word and an available concept (or set of concepts), and acquiring an inferential connective such as but or so involves establishing a link between a new word and an available procedure (or set of procedures). Which word goes with which concept or procedure is an arbitrary matter that has to be learned in the course of acquiring a language, and therefore falls on the decoding side of the decoding-inference distinction. In that sense, the relation between a linguistic expression and the concept or procedure it encodes is properly regarded as semantic.

On this approach, linguistic semantics is at the interface between the language system and the rest of the cognitive system, which is standardly seen as comprising a set of conceptual representations, on the one hand, and a set of procedures, on the other. In our book Relevance, Dan Sperber and I made some general comments on how semantic interpretation might be viewed in a cognitive system of this type:

... a language is a set of semantically interpreted well-formed formulas. A formula is semantically interpreted by being put into systematic correspondence with other objects: for example, with the formulas of another language, with states of the user of the language, or with possible states of the world. (Sperber and Wilson, 1986/1995:172-3)

Here, "language" covers both public languages and the internalised conceptual representation system or 'language of thought', and a "formula" in a language is a constituent of that language (e.g. a word of French, or a concept in the 'language of thought'). As noted in 
Wilson (2011), it seems plausible to assume that all three types of systematic correspondence are exploited in linguistic communication, in the following way:

(13) a. Conceptual expressions in a public language (e.g. scarlet, hop) are systematically linked to concepts (e.g. SCARLET, HOP), which are constituents of a language of thought.

b. Sentences in the language of thought (e.g. GIRAFFES HOP) are systematically linked to possible states of the world.

c. Procedural expressions in natural language (e.g. but, so) are systematically linked to states of language users.

The first two hypotheses are fairly standard: it is widely assumed that 'content' words get their meanings by encoding concepts, and that thoughts get their content by representing possible states of the world. The hypothesis I want to elaborate on is (13c), the idea that procedural expressions in a public language are semantically interpreted by being put into systematic correspondence with states of the language user.

On many current approaches to cognitive science (e.g. Barkow, Cosmides and Tooby, 1992; Sperber, 2005; Carruthers, 2006; Mercier and Sperber, forthcoming), the human cognitive system is seen as comprising a large array of domain-specific inferential procedures with distinct developmental trajectories and breakdown patterns, which may be more or less highly activated in different circumstances and are likely to alter their level of activation in response to different cues. As Mercier and Sperber (2011:58) put it,

An evolutionary approach suggests that inferential processes, rather than being based on a single inferential mechanism or constituting a single integrated system, are much more likely to be performed by a variety of domain-specific mechanisms, each attuned to the specific demands and affordances of its domain.

Among the possible states of the user of a language will be those in which a certain inferential mechanism or procedure is highly activated. According to hypothesis (13c), the function of the procedural expressions in a language is to put the user of the language into a state in which some of these domain-specific inferential procedures are highly activated (and hence more likely to play a role in a relevance-oriented comprehension process). Thus, procedural expressions act as 'pointers' to certain procedures.

As suggested in Wilson (2011), this hypothesis might help to explain certain differences in the behaviour of conceptual and procedural expressions that have been noticed in the literature. For instance, conceptual representations are often described as capable of being brought to consciousness, reflected on and used in general inference. If words such as scarlet or hop encode concepts, i.e. constituents of conceptual representations, this might help to explain the relative transparency of their relation to thoughts (Wilson and Sperber, 1993:16). By contrast, domain-specific cognitive procedures are generally seen as either purely dispositional or formulated in a sub-personal 'machine language' distinct from the language 
of thought, which is relatively inaccessible to consciousness and resistant to conceptualisation. If the function of connectives such as but and so is to activate such procedures, this would help to explain why their meanings are relatively inaccessible to consciousness and are notoriously hard to pin down in conceptual terms (Wilson and Sperber 1993:16). ${ }^{8}$ Moreover, the idea that acquisition of conceptual expressions depends on the availability of the associated concepts while acquisition of procedural expressions depends on the availability of the associated procedures may shed some light on subtle differences in the acquisition of grammaticalised vs. lexicalised expressions such as those discussed by Matsui and Miura (2009) and Matsui et al. (this issue).

In this section, I have suggested that the function of procedural expressions is to activate domain-specific procedures which may be exploited in inferential communication. Standard relevance-theoretic accounts take a fairly restrictive view of the type of procedures involved. According to this standard view, the function of procedural expressions is to activate procedures whose main function is to help the hearer understand an utterance by finding the intended combination of context, explicit content and cognitive effects. In the light of recent 'massive modularity' accounts on which both concepts and procedures are seen as evolving in response to different regularities in the environment, and therefore as heavily domain specific, it is worth considering whether procedural expressions may be used to activate cognitive procedures whose primary functions are not intrinsically linked to inferential comprehension. In a later section, I will discuss the possibility that languages typically contain clusters of procedural expressions linked to procedures or mechanisms from different cognitive domains. Here, I hope to have shown that it is worth distinguishing what is encoded from the nature of the encoding relation itself. Whereas the encoding relation is properly regarded as part of linguistic semantics, its outputs - whether concepts or procedures - are not.

\section{Interjections, procedural encoding and conventions for use}

Among the items that both procedural and use-conditional semanticists see as central to their concerns are interjections, discourse particles and mood indicators. In this section, I will make some comparisons between the types of analysis they propose, using interjections as an illustration.

Kaplan (1999, 2004) suggests that instead of asking what an interjection means, we should ask what are the conditions under which it is "correctly", "accurately" or "felicitously" used. He sees the meanings of interjections - and use conditions more generally - as a matter of convention, adding, "To the degree that such conditions reflect linguistic convention, the information that such a condition obtains is carried in the semantics of the expression" (Kaplan, 2004:3). He analyses two interjections - ouch and oops - in use-conditional terms.

\footnotetext{
${ }^{8}$ This is sometimes called the "descriptive ineffability" issue (Potts, 2007; Blakemore, 2011). Drozdzowicz (2015) argues, correctly in my view, that descriptive ineffability is merely a piece of evidence, and not a criterion for distinguishing conceptual from procedural meaning.
} 
Here is his analysis for ouch (the quotation is taken from the transcript of a public lecture, hence the informal tone):

I take it that the rule for ouch is reasonably simple: That the speaker has just experienced probably a sudden and sharp pain. I'm not going to worry too much about giving exact ... how precise the analysis is; I wanna get a rough cut at it. (Kaplan, 2004:10)

On this approach, as he points out, ouch is informationally equivalent to the sentence I am in pain, and is "expressively correct" in all those contexts where the speaker is in pain.

However, it lacks a truth value even in contexts where it is expressively correct, since it falls within the scope of a "Theory of Use" rather than a "Theory of Meaning".

As the above quotation makes clear, Kaplan's aim is not to give a precise analysis of the full range of use conditions for ouch. He is aware that it can be appropriately used in ways that do not fit the proposed pattern, as in what he calls the "empathetic" use, where ouch is uttered in response to the perception of someone else in pain. He describes this as a "trope", and hopes that it "need not be the concern of logic, which is grounded more in the literal use of language than in things like an empathetic use" (Kaplan, 2004:11). This raises the question of where the borderline between 'literal' and 'figurative' uses of interjections should be drawn, and how the 'figurative' uses are derived. For instance, ouch can be appropriately used when the pain is mental rather than physical, as in (14), from Wharton (2009:83):

(14) a. Dentist: That' 11 be $£ 75$ for the consultation and $£ 30$ for the cavity.

b. Patient: Ouch!

Depending on how pain is interpreted in the use conditions for ouch, this could be seen as either a literal use (where pain can be either mental or physical) or a metaphorical use (involving a broadening of the literal meaning of pain). There are also many further uses which do not fit Kaplan's proposed pattern but do not seem obviously figurative either, as in (15):

(15) a. Every time I wake up with a hangover, ouch! I reach for an aspirin.

b. Last New Year's Day I woke up with a hangover and ouch! I really felt it.

c. Tomorrow you'll wake up with a hangover and ouch! you'll really regret how much you drank tonight.

An alternative account of ouch which would handle the full range of examples and fit well with the procedural analysis proposed by Tim Wharton (2003a, 2009, this issue) might start from the assumption that ouch is not informationally equivalent to I am in pain, but is used instead to communicate the speaker's attitude or reaction to the experience, memory or prospect of pain (whether physical or mental). As Wharton notes, interjections are typically accompanied by affective intonation, which helps to calibrate the intensity of the reaction and the range and type of emotions or attitudes conveyed. However, affective intonation is not 
generally considered properly linguistic, and to the limited extent that its use is governed by convention, the conventions are social rather than linguistic. This raises a question that Wharton discusses in some detail: are interjections properly linguistic, and do their uses reflect what Kaplan calls "linguistic convention" at all?

Relevance-theoretic approaches to interjections have a very different flavour from Kaplan's. Relevance theorists have been interested in whether they are properly linguistic (and whether only properly linguistic expressions can encode procedural information), whether the type of communication they involve is necessarily ostensive, to what extent they fall together with 'natural signals' such as affective intonation or facial expressions of emotion, which are not themselves inherently ostensive, and so on (e.g. Wharton, 2003a, 2009, this issue; Walaszewska, 2004; Padilla Cruz, 2009). For instance, Wharton (2009:103) argues that the meanings of interjections are "partly natural and partly coded", and that they fall "at various points along a continuum between display and language proper". In his view, interjections are not in general a part of language, although their partly coded nature means that they might be seen as "existing on the edge of language, integrated to a greater or lesser extent". This brings out their similarities to intonation, which is also widely seen as existing on a continuum between the natural and the properly linguistic (e.g. Pell, 2002, 2006; Gussenhoven, 2004; Wilson and Wharton, 2006).

If interjections turn out to be not properly linguistic, the consequences for procedural semantics and use-conditional semantics would be rather different. As pointed out in section 3 , the inferential procedures discussed in procedural semantics are not themselves properly linguistic, and it is quite reasonable to suppose that they may be triggered by non-linguistic as well as linguistic cues. For instance, 'natural signals' such as affective intonation and facial expressions of emotion are often seen as governed by 'natural codes' of the type involved in animal communication systems such as the bee dance (Wharton, 2003b, 2009; Scott-Phillips, 2015). In a procedural approach to semantics, these 'natural codes' should be straightforwardly analysable in procedural terms, as involving systematic correspondences between 'natural signals' and states of the user or perceiver. In this framework, procedural analyses should be equally applicable to public language expressions, interjections (whether properly linguistic or not), and 'natural signals' such as affective intonation and facial expressions of emotion, which are not inherently ostensive. By contrast, the claim that affective intonation and facial expressions of emotion can be explained in terms of something comparable to linguistic conventions seems far-fetched at best. Here, the differences between approaches based on an extension of semantics and those linked to a theory of communication such as relevance theory seem quite clear.

\section{Lexical pragmatics and the conceptual-procedural distinction}

The development of the conceptual-procedural distinction within relevance theory was influenced by the work of Oswald Ducrot and his colleagues, who were pursuing the idea that many or most expressions in a language have not only conceptual content but also an inferential or argumentative orientation, which in relevance theory would be analysed in 
procedural terms (Ducrot, 1972, 1980; Anscombre and Ducrot, 1983). Although commentators on relevance theory sometimes assume that the conceptual-procedural distinction was intended to be mutually exclusive, so that a single word cannot encode both types of meaning, there are several reasons for thinking that conceptual and procedural information may combine in the semantics of a single expression.

To take just one example, Ducrot (1972) analyses the French equivalents of pairs such as few and $a$ few in utterances like the following:

(16) a. Pierre had few drinks: he was quite abstemious.

b. $\quad$ ?Pierre had a few drinks: he was quite abstemious.

(17) a. ?Pierre had few drinks: he got drunk quite early.

b. $\quad$ Pierre had a few drinks: he got drunk quite early.

Here, few and a few carry similar information about quantity, which affects the truth conditions of utterances and is plausibly treated as conceptual. However, they also impose what Ducrot and colleagues call an "argumentative orientation", which accounts for the differences in acceptability illustrated in (16)-(17). Describing Pierre as having had few drinks orients the hearer towards the conclusion that he was quite abstemious, whereas describing him as having a few drinks orients the hearer in the opposite direction. This seems to be a fact about the semantics of few vs. a few, which must be acquired in the course of learning the language. Thus, few and a few (and comparable pairs such as little / a little, almost / barely and so on) provide some evidence that conceptual and procedural meaning can combine in the analysis of a single word.

Other candidates for mixed conceptual-procedural analysis include some items of particular interest to use-conditional theorists: ethnic slurs such as Kraut, which shares its denotation with German but carries an additional expressive element, and a range of further items which share their denotations but differ in the attitudes or evaluations they convey, e.g. dog vs cur, violin vs fiddle, horse vs steed, and so on (Potts, 2007; Blakemore 2011, 2015; Gutzmann, 2015; Wharton, this issue). Use-conditional semantics should be particularly valuable in examining the contribution of these hybrid expressions to the interpretation of utterances as a whole.

The idea that a single word can encode both conceptual and procedural information might be extended in several ways. In fact, Ducrot ended up proposing that all 'content' words may carry procedural information, and there has been some debate in relevance theory about this suggestion. In a discussion on the relevance e-mail list (Relevance e-mail Archives, 3.12.2007), Dan Sperber commented that it "would not be inconsistent" for relevance theorists to adopt Ducrot's proposal, or at least to adapt it along the following lines:

(18) a. Assume that all lexical items encode procedures (whether or not they also encode conceptual content, as most of them do). 
b. When conceptual information is encoded, so is an instruction to inferentially construct an ad hoc concept using the encoded conceptual content as a starting point.

c. Other instructions of the type familiar from Diane Blakemore's work may be encoded by any word, whether or not it also encodes conceptual content.

On this approach, most words would encode some procedural content. Some would also encode conceptual content, whereas others (e.g. however) would not. Among words that encode both procedural and conceptual content, some (e.g. hop) would automatically trigger a procedure for constructing an ad hoc concept on the basis of the encoded concept, ${ }^{9}$ whereas others (e.g. unless) might encode a more specific procedure of the type discussed in sections 2-4 above.

Although the idea that all lexical items might encode procedural information is quite speculative, it does seem to offer some advantages that make it worth taking seriously. In the first place, it would shed light on a claim often made in relevance theory, that the occurrence of a word in an utterance is a 'pointer to', or a 'piece of evidence about', the speaker's meaning, as in the following comment from Sperber and Wilson (1998:196):

Quite generally, the occurrence of a word in an utterance provides a piece of evidence, a pointer to a concept involved in the speaker's meaning. It may so happen that the intended concept is the very one encoded by the word, which is therefore used in its strictly literal sense. However, we would argue that this is no more than a possibility, not a preferred or default interpretation.

It would be interesting to compare this idea with another hypothesis currently being considered in the literature, that many words encode 'pro-concepts', which are semantically incomplete and have to be fleshed out into full concepts using available contextual information. Discussing this hypothesis, Sperber and Wilson (1998:185) comment,

We believe that pro-concepts are quite common, but the argument of this chapter does not depend on that assumption (or even on the existence of pro-concepts). What we will argue is that, quite commonly, all words behave as if they encoded pro-concepts: that is, whether or not a word encodes a full concept, the concept it is used to convey in a given utterance has to be contextually worked out.

The idea that most 'content' words encode not only a concept but also a procedure for ad hoc concept construction suggests one way of implementing this proposal (for discussion, see Carston, 2012, 2013, this issue).

\footnotetext{
${ }^{9}$ Relevance theorists have argued for some time that the interpretation of every 'content' word is finetuned in context (Wilson and Carston, 2007; Sperber and Wilson, 2008; Jodlowiec, 2015;

Walaszewska, 2015). The suggestion in (18b) is that the processing of a 'content' word might automatically activate such a fine-tuning procedure.
} 
The same idea might shed some light on historical processes such as grammaticalization, where a lexical item gradually loses some or all of its conceptual content and acquires a purely grammatical function (Traugott and Heine, 1991; Hopper and Traugott, 2003). For instance, König and Traugott (1982:172) provide evidence that still was used in Old English only as an adjective or adverb with the meaning 'still, quietly'; the adverb still developed a temporal sense in Middle English and a purely concessive use in Early Modern English The tendency of temporal connectives such as since, as, while, still and then to give rise to purely inferential uses has been observed in many languages, and various pragmatic explanations have been proposed. In a framework where much of the conceptual vocabulary is seen as entirely lacking in procedural content, the historical process by which an adverb such as still or a noun such as while gives rise to a temporal and then a ppurely inferential connective must be seen as involving a switch at some point from conceptual to procedural status. The framework offers no obvious way of explaining why such a switch should take place, or why it typically goes in one direction (i.e. from conceptual to procedural) rather than the other. In a framework where all 'content' words would start out with at least some procedural content, it is easy to see how more specific procedures might be added over time, to a point where the original conceptual content becomes entirely redundant (these points are insightfully discussed in Nicolle, 1998; Breul, 2007; Clark, this isssue).

I have tried to show in this section that the assumption that some expressions encode both conceptual and procedural meaning has definite advantages for lexical pragmatics. I have also tentatively suggested that the assumption that all conceptual expressions encode procedural meaning might bring further advantages, and is worth investigating further. In the next section, I will look more closely at the relation between argumentative orientation and procedural meaning, and discuss some further possible revisions or extensions. Before moving on, though, it is worth pointing out that the type of procedural information discussed in this section would be extremely hard to translate into conditions on appropriate use of the type that Kaplan and his colleagues have discussed. As noted above, Kaplan sees semantics as concerned with conditions on literal use, whereas the type of procedural information described in (18a)-(18b) constrains the pragmatic process of lexical modulation, which accounts for narrowed, approximate, hyperbolic and metaphorical uses, and therefore crosses the 'literal-figurative' divide. This is not the sort of information that could be captured in a strictly linguistic or semantic convention, and in this case, use-conditional semantics and procedural semantics again come apart.

\section{Massive modularity and the conceptual-procedural distinction}

A massively modular mind is characterised by a wide array of special-purpose cognitive mechanisms or modules adapted to regularities in different domains. In section 3, I suggested that the function of procedural expressions may be to activate such domain-specific procedures, which are likely to be drawn from modules (or sub-modules) which play a significant role in linguistic communication: for instance, those involved in mindreading, emotion reading, social cognition, parsing and speech production and inferential 
comprehension. One consequence of this suggestion is that we might expect to find clusters of procedural items linked to different domain-specific capacities. And indeed, this seems to be just what we find.

For instance, most languages have a cluster of procedural items (e.g. affective intonation, interjections, attitudinal particles) associated with domain-specific mechanisms for emotion reading. Most languages also have a cluster of procedural items (e.g. mood indicators, which may be realised by grammaticalised particles or morphemes, by word order or simply by intonation) associated with domain-specific mechanisms for attributing mental states on the basis of behavioural cues. Languages with grammaticalised honorific systems contain a further cluster of procedural expressions which might be seen as linked to domain-specific mechanisms for social cognition. Notice that the capacities for mindreading, emotion reading and social cognition are not intrinsically linked to ostensive communication: for instance, we attribute mental or emotional states to others whether or not they are communicating with us.

Two further capacities that have received considerable attention in recent years are those for argumentation and epistemic vigilance. The argumentative capacity involves "a mechanism for representing possible reasons to accept a conclusion ... and for evaluating their strength" (Mercier and Sperber, 2011:58). It is important to distinguish arguments from inferences, or inferential procedures, of the type discussed by Blakemore (1987, 2002). As Mercier and Sperber put it,

An inference is a process the output of which is a representation. An argument is a complex representation. Both an inference and an argument have what can be called a conclusion, but in the case of an inference, the conclusion is the output of the inference; in the case of an argument, the conclusion is a part - typically the last part - of the representation. (Mercier and Sperber, 2011: 58).

That is, inferences are procedural, while arguments are representational.

The capacity for epistemic vigilance involves "a suite of cognitive mechanisms ... targeted at the risk of being misinformed by others" (Sperber et al., 2010:359). Whereas the argumentative capacity is of benefit to both speakers and hearers, epistemic vigilance is primarily of benefit to hearers, who are seen as possessing domain-specific mechanisms geared to evaluating the reliability of the communicator, on the one hand, and the communicated information, on the other.

Suppose, now, that I want you to believe a certain proposition although I know it conflicts with some background assumption you have in mind. One way to persuade you would be to produce an argument showing that this proposition follows logically from, or is strongly supported by, other background information you have available that you would be reluctant to give up. Producing an argument of this type would involve the use of logical or inferential connectives to display the intended logical or evidential relations. As Sperber (2001:410) puts it, 
Displaying [logical/evidential relations] requires an argumentative form, the use of logical terms such as if, and, or and unless, and of words indicating inferential relationships such as therefore, since, but, and nevertheless. It is generally taken for granted that the logical and inferential vocabulary is - and presumably emerged as - a tool for reflection and reasoning. From an evolutionary point of view, this is not particularly plausible. The hypothesis that such terms emerged as tools for persuasion may be easier to defend.

This sheds new light on the standard relevance-theoretic account of inferential connectives such as but and so, on which their main function is to activate procedures which guide the hearer's path in inferential comprehension. It suggests, in fact, that these inferential connectives might contribute to comprehension in two rather different ways. On the one hand, the inferential relationships they indicate may remain in the background of the comprehension process, so that the addressee simply draws the appropriate conclusions without thinking about the reasons for drawing them. In that case, the connectives would contribute to relevance mainly on the effort-saving side, by narrowing the search space for appropriate contextual assumptions and cognitive effects, and this is how they have generally been seen in relevance theory. On the other hand, the existence of the inferential relationships indicated by these connectives may be relevant enough in its own right to be worth the addressee's attention, so that he not only draws the appropriate conclusions but thinks about the reasons for drawing them, and goes on to derive further conclusions that would not otherwise have been derived. In that case, the connectives might contribute to relevance not only by saving effort but by contributing new effects. I will return to this point in section 7 .

As noted above, the capacity for epistemic vigilance is primarily of benefit to hearers, and involves a suite of mechanisms geared to assessing not only the strength and validity of arguments, but also the reliability, honesty and trustworthiness of the speaker. It is in the interest of speakers to appear generally reliable, honest and trustworthy. If we regularly interact with the same people, giving them false or inaccurate information (even if it is to our own immediate advantage) may damage our reputation and end up being costly in the long run. Conversely, doing our best to be systematically trustworthy may cost us some immediate benefit, but may be beneficial in the long run. The trade-off between the short term costs and long term benefits of a policy of trustworthiness may vary from person to person, so that different speakers may end up following different policies. However, speakers who opt for a policy of systematic trustworthiness would stand to benefit from a reputation for being highly trustworthy, which would be fed by common knowledge of their past actions, and might be advertised by their everyday public behaviour and demeanour.

Suppose, now, that I want you to believe some proposition, but I am not sure you will take my word for it in the absence of any information about the type of evidence I have available or my reliability on that topic. An obvious way to persuade you would be to display openly the type of evidence I have, or my degree of confidence in the truth of my assertion, by using linguistic indicators of epistemic modality or evidentiality (Aikhenvald, 2004; Fitneva and 
Matsui, 2009). Seen in this light, the function of evidentials and epistemic modals would be not so much to guide the comprehension process (since the proposition expressed by the utterance would have been understood just as well without them) as to display the communicator's competence, benevolence and trustworthiness to the hearer.

Some support for this suggestion comes from comments by speakers of languages with grammaticalised evidential systems in which the use of evidentials is obligatory. According to Alexandra Aikhenvald (2004:336), in languages of this type, "getting one's evidentials right is important for one's status and credibility":

Ignoring evidentiality in a language with evidentials gets you marked as unreliable or a liar. (Aikhenvald, 2004:344)

Accuracy in getting one's information source right is crucial for successful communication, and for the speaker's reputation. (ibid.:335)

Or, as Silver and Miller (1997: 37) put it,

In the use of evidentials, the issue is not morality, or truth, it is accuracy.

These comments suggest that evidentials have more to do with getting the addressee to trust the speaker than with helping him to understand her, and this idea would be worth exploring further.

\section{Concluding remarks}

As I have presented it in this paper, the cognitive distinction between conceptual and procedural information cross-cuts the distinction between truth-conditional and non-truthconditional meaning, and is in some ways more fundamental. In this framework, the primary bearers of truth-conditional content are not utterances or speech acts but conceptual representations, and intuitions about the truth-conditional content of utterances or speech acts are often bound up with pragmatic inferences about which of the many propositions an utterance makes manifest is the one on which its main relevance depends. These intuitions have played a significant role in debates about the truth-conditional or non-truth-conditional status of appositives, parentheticals and inferential connectives, and in distinguishing basic explicatures from higher-order explicatures in utterances such as (19), where the main relevance may depend on either the proposition that I'm leaving or the proposition that I'm telling you I'm leaving (Wilson, 2000; Ifantidou, 2001; Iten, 2005):

I tell you I'm leaving.

Although use-conditional theorists are mainly concerned with the distinction between truthconditional and non-truth-conditional meaning, it is fairly easy to see how the notion of conceptual meaning might fit with their framework, and by far the biggest differences 
between use-conditional and procedural semantics fall on the expressive/ procedural side. Formal semanticists in general tend to appeal to representations rather than processes: thus, attempts to incorporate Grice's notion of conventional implicature into formal semantics have treated it (as he seems to have done himself) in conceptual rather than procedural terms (e.g. as contributing to some other level of conceptual information than "at issue" content, cf. Potts, 2005). Blakemore's reanalysis of conventional implicatures in procedural terms was genuinely original. I have tried to show that in many cases, procedural analyses are neither equivalent to nor translatable into use-conditional analyses à la Kaplan, and that the two approaches to semantics are genuinely distinct. So far in relevance theory, the null hypothesis has been that words encode concepts, and only if conceptual analysis proves impossible or unwieldy would a procedural analysis be considered. But from the perspective of a theory of ostensive communication, where a public language is just one tool among many for getting the speaker's meaning across, we might reasonably expect languages to contain all sorts of devices which merely point the addressee in the right direction rather than providing a full concept as a starting point for inference. The suggestion that procedures may be triggered by non-linguistic cues, and that all linguistic expressions might be procedural to some extent, is a step in this direction.

Let us return, finally, to the status of so and therefore, which as illustrated in (11) and (12) (repeated here) seem sometimes to affect truth-conditional content and at other times not:

(11) a. If Lisa is French and therefore a citizen of the European Union, she can travel to Germany without a passport.

b. If Lisa is French and so a citizen of the European Union, she can travel to Germany without a passport.

c. If Lisa is French and a citizen of the European Union, she can travel to Germany without a passport.

(12) a. If the council fails to repair a pothole and you therefore break your leg, you should sue.

b. If the council fails to repair a pothole and so you break your leg, you should sue.

c. If the council fails to repair a pothole and you break your leg, you should sue.

I suggested that in (11a)-(11b), there is a clear intuition that therefore and so do not affect the truth conditions of the utterance (i.e. they do not fall within the scope of $i f$ ), while in (12a)(12b), there is a clear intuition that they do. Does this mean we have to resort to an ambiguity account on which so and therefore have two distinct senses, one conceptual and truthconditional and the other procedural and non-truth-conditional? Before moving in that direction, it is worth reflecting on the two ways in which an inferential connective may contribute to relevance, as discussed in section 6 above. In (11a)-(11b), the use of so and therefore indicates that there is an inferential relationship between being French and being a citizen of the European Union, a fact which might already have been manifest to the addressee of (11c) in the absence of any connective. Similarly, in (12a)-(12b), the use of so and therefore indicates that there is an inferential relationship between the council's failing to 
repair a pothole and the addressee's breaking his leg, a possibility which might already have been manifest to the addressee of (12c) in the absence of any connective. The difference between (11) and (12) is that in (11a)-(11c), the inferential relationship indicated by the use of the connectives remains in the background and the contribution of the connectives to relevance is mainly on the effort-saving side, whereas in (12a)-(12c), the inferential relationship indicated by the use of the connectives is relevant enough in its own right to be worth the hearer's attention, and as shown by (12c), must be inferred even in the absence of the connectives in order to satisfy the addressee's expectations of relevance. On this approach, the truth-conditional status of so and therefore is like the truth-conditional status of I tell you in (19): intuitions about their contributions to truth-conditional content are bound up with intuitions about where the main relevance of the utterance lies.

\section{Acknowledgements}

My greatest thanks are to Diane Blakemore for friendship, fun and inspiration over many years. I would also like to thank Dan Sperber, Tim Wharton, Steve Nicolle, Ewa Walaszewska and two anonymous referees for valuable comments on an earlier version.

\section{References}

Aikhenvald, A., 2004. Evidentiality. Oxford University Press, Oxford.

Anscombre, J.-C, Ducrot, O., 1977. Deux 'mais' en français? Lingua 43, 23-40.

Anscombre, J.-C., Ducrot, O., 1983. L'argumentation dans la langue. Mardaga, Paris.

Ariel, M., 2010. Defining Pragmatics. Cambridge University Press, Cambridge.

Bach, K., 1999. The myth of conventional implicature. Linguistics and Philosophy 22, 327-366.

Barkow, J. H., Cosmides, L., Tooby, J., (Eds.), 1992. The Adapted Mind. Oxford University Press, Oxford.

Bezuidenhout, A., 2004. Procedural meaning and the semantics/pragmatics interface. In: Bianchi, C. (Ed.), The Semantics/Pragmatics Distinction. CSLI, Stanford, CA, pp. 101-131.

Blakemore, D., 1987. Semantic Constraints on Relevance. Blackwell, Oxford.

Blakemore, D., 1993. The relevance of reformulations. Language and Literature 2, 101-120.

Blakemore, D., 2002. Relevance and Linguistic Meaning: The Semantics and Pragmatics of Discourse Markers. Cambridge University Press, Cambridge.

Blakemore, D., 2011. On the descriptive ineffability of expressive meaning. Journal of Pragmatics 43, 3537-3550.

Blakemore, D., 2015. Slurs and expletives: A case against a general account of expressive meaning. Language Sciences 52, 22-35.

Blass, R., 1990. Relevance Relations in Discourse: A Study with Special Reference to Sissala. Cambridge University Press, Cambridge.

Breul, C., 2007. A relevance-theoretic view on the history of clausal connectives. In: Lenker, U., Meurman-Solin, A. (Eds.), Connectives in the History of English. John Benjamins, Amsterdam. Carruthers, P., 2006. The Architecture of the Mind. Oxford University Press, Oxford.

Carston, R., 2002. Thoughts and Utterances: The Pragmatics of Explicit Communication. Blackwell, Oxford.

Carston, R., 2012. Word meaning and concept expressed. The Linguistic Review 29, 607-623. 
Carston, R., 2013. Word meaning, what is said and explicature. In: Penco, C., Domaneschi, F. (Eds.), What is Said and What is Not. CSLI Publications, Stanford, CA, pp. 175-203.

Carston, R. this issue. The heterogeneity of procedural meaning. To appear in Lingua.

Clark, B., this issue. Relevance theory and language change. To appear in Lingua.

Dennett, D., 1981. Brain writing and mind reading. In: Dennett, D., Brainstorms: Philosophical

Essays on Mind and Psychology. MIT Press, Cambridge, MA, 39-50.

Drozdzowicz, A., 2015. Investigating utterance meaning: Investigations in the epistemology of

language. PhD. dissertation, University of Oslo.

Ducrot, O., 1972. Dire et ne pas dire: Principes de sémantique linguistique. Hermann, Paris.

Ducrot, O., 1980. Les mots du discours. Editions de Minuit, Paris.

Escandell-Vidal, V. 2002. Echo-syntax and metarepresentations. Lingua 112, 871-900.

Escandell-Vidal, V., Leonetti, M., Ahern, A. (Eds.), 2011. Procedural Meaning: Problems and

Perspectives. Current Research in the Semantics-Pragmatics Interface, vol. 25. Brill, Leiden.

Fitneva, S., Matsui, M. (Eds.). 2009. Evidentiality: A Window into Language and Cognitive Development. Wiley, San Francisco, CA.

Frege, G., 1892. On sense and reference. Reprinted in Moore, A. W. (Ed.), 1993: Meaning and

Reference. Oxford University Press, Oxford, pp 23-42.

Gazdar, G., 1979. Pragmatics: Implicature, Presupposition and Logical Form. Academic Press, New York, NY.

Grice, H.P., 1989. Studies in the Way of Words. Harvard University Press, Cambridge, MA.

Gussenhoven, C., 2004. The Phonology of Tone and Intonation. Cambridge University Press, Cambridge.

Gutt, E.-A., 1991. Translation and Relevance: Cognition and Context. Blackwell, Oxford. (2 ${ }^{\text {nd }}$ edition, St Jerome Press, 2000)

Gutzmann, D., 2015. Use-Conditional Meaning: Studies in Multi-Dimensional Semantics. Oxford University Press, Oxford

Gutzmann, D., Gärtner, H.-M. (Eds.), 2013. Beyond Expressives: Explorations in Use-Conditional Meaning. Current Research in the Semantics-Pragmatics Interface, vol. 28. Brill, Leiden.

Hall, A., 2007. Do discourse connectives encode concepts or procedures? Lingua 117, 149-174.

Hopper, P., Traugott, E., 2003. Grammaticalization. Cambridge University Press, Cambridge.

Horn, L., 2007. Toward a Fregean pragmatics: Voraussetzung, Nebengedanke, Andeutung. In:

Keksces, I., Horn, L. (Eds.), Explorations in Pragmatics. Mouton de Gruyter, Berlin, pp, 39-69.

Ifantidou, E., 2001. Evidentials and Relevance. John Benjamins, Amsterdam.

Iten, C., 2005. Linguistic Meaning, Truth Conditions and Relevance: The Case of Concessives.

Palgrave, Basingstoke.

Jary, M., 2011., Assertion, relevance, and the declarative mood. In: Escandell-Vidal et al., pp. 267289.

Jodlowiec, M., 2015. The Challenges of Explicit and Implicit Communication: A RelevanceTheoretic Approach. Peter Lang, Frankfurt.

Kaplan, D. 1989. Demonstratives. In: Almog, J., Perry, J., Wettstein, H. (Eds,), Themes from Kaplan. Oxford University Press, New York, NY, pp. 267-298.

Kaplan, D., 1999. What is meaning? Explorations in the theory of Meaning as Use. Brief version draft 1, Ms., UCLA.

Kaplan, D., 2004. The meaning of ouch and oops. Howison Lectures in Philosophy, University of California, Berkeley. http://gradlectures.berkeley.edu/lecture/the-meaning-of-ouch-and-oops/

König, E., Traugott, E., 1982. Divergence and apparent convergence in the meaning of yet and still. Proceedings of the Eighth Annual Meeting of the Berkeley Linguistics Society, pp. 170-179.

Kripke, S., 1982. Wittgenstein on Rules and Private Languages. Blackwell, Oxford. 
Matsui, T., Miura, Y., 2009. Children's understanding of certainty and evidentiality: Advantage of grammaticalised forms over lexical alternatives. In: Fitneva, E., Matsui, T. (Eds.), pp. 49-62.

Matsui, T., Yamamoto, T., Miura, Y., McCagg, P., this issue. Young children's early sensitivity to indications of speaker certainty in their selective word learning. To appear in Lingua (this issue).

Mercier, H., Sperber, D., 2011. Why do humans reason? Arguments for an argumentative theory. Behavioral and Brain Sciences 34, 57-74.

Mercier, H., Sperber, D. forthcoming. The Enigma of Reason. Ms.

Nicolle, S. 1998. A relevance theory perspective on grammaticalization. Cognitive Linguistics 9, 135 .

Padilla Cruz, M., 2009. Towards an alternative relevance-theoretic approach to interjections. International Review of Pragmatics 1, 182-206.

Pell, M., 2002. Surveying emotional prosody in the brain. In: Bel, B, Marlien, I. (Eds.) Proceedings of the Speech Prosody 2002 Conference, pp. 77-82.

Pell, M., 2006. Prosody-face interactions in emotional processing as revealed by the facial affect decision task. Journal of Nonverbal Behavior 29, 45-73.

Potts, C., 2005. The Logic of Conventional Implicatures. Oxford University Press, Oxford.

Potts, C., 2007. The expressive dimension. Theoretical Linguistics 33, 165-197.

Powell, G., 2010. Language, Thought and Reference. Palgrave, Basingstoke.

Scott, K., 2011. Beyond reference: Concepts, procedures and referring expressions. In: EscandellVidal et al., pp. 183-203.

Scott, K., 2013. This and that: A procedural analysis. Lingua 131, 49-65.

Scott, K., this issue. Pronouns and procedures: Reference and beyond. To appear in Lingua.

Scott-Phillips, T. 2015. Speaking our Minds: Why Human Communication is Different, and How Language Evolved to Make it Special. Palgrave Macmillan, Basingstoke.

Silver, S., Miller, W., 1997. American Indian Languages: Cultural and Social Contexts. University of Arizona Press, Tucson, AZ.

Sperber, D. 2001. An evolutionary perspective on testimony and argumentation. Philosophical Topics 29, 401-413.

Sperber, D., 2005. Modularity and relevance: How can a massively modular mind be flexible and context dependent? In: Carruthers, P., Laurence, S., Stich, S. (Eds.) The Innate Mind. Oxford University Press, Oxford, pp. 53-68.

Sperber, D., Clément, F., Heintz, C., Mascaro, O., Mercier, H., Origgi, G., Wilson, D., 2010. Epistemic vigilance. Mind and Language 25, 359-393.

Sperber, D., Wilson, D., 1986. Relevance: Communication and Cognition. Blackwell, Oxford. (2 ${ }^{\text {nd }}$ edition 1995.)

Sperber, D., Wilson, D., 1988. Mood and the analysis of non-declarative sentences. In: Dancy, J., Moravcsik, J., Taylor, C.C.W. (Eds.), Human Agency: Language, Duty and Value. Stanford University Press, Stanford, CA, pp. 77-101. (Reprinted in Wilson and Sperber 2012, pp. 210229.

Sperber, D., Wilson, D., 1998. The mapping between the mental and the public lexicon. In: Carruthers, P., Boucher, J. (Eds.), Language and Thought: Interdisciplinary Themes. Cambridge University Press, Cambridge, pp. 184-200. (Reprinted in Wilson and Sperber 2012, pp. 31-46^-

Sperber, D., Wilson, D., 2008. A deflationary account of metaphors. In: Gibbs, R. (Ed.), The Cambridge Handbook of Metaphor and Thought. Cambridge University Press, Cambridge, pp. 84-105. (Reprinted in Wilson and Sperber 2012, pp. 97-122.)

Sperber, D., Wilson, D., 2015. Beyond speaker's meaning. Croatian Journal of Philosophy, XV, 44, 117-149. 
Traugott, E., Heine, B. (Eds.), 1991. Approaches to Grammaticalization. John Benjamins, Amsterdam.

Unger, C., 2011. Exploring the borderline between procedural encoding and pragmatic inference. In: Escandell-Vidal et al., pp. 103-127.

Walaszewska, E., 2004. What to do with response cries in relevance theory? In: Mioduszewska, E. (Ed.), Relevance Studies in Poland, vol. I. University of Warsaw, Warsaw.

Walaszewska, E., 2015. Relevance-Theoretic Lexical Pragmatics: Theory and Applications. Cambridge Scholars Press, Newcastle.

Wharton, T., 2003a. Interjections, language and the 'showing'/'saying' continuum. Pragmatics and Cognition 11, 39-91.

Wharton, T., 2003b. Natural pragmatics and natural codes. Mind and Language 18, 447-477.

Wharton, T., 2009. Pragmatics and Non-Verbal Communication. Cambridge University Press, Cambridge.

Wharton, T. this issue. That bloody so-and-so has retired - Expressives revisited. To appear in Lingua.

Wilson, D. 2000. Metarepresentation in linguistic communication. In Sperber, D. (Ed.), Metarepresentations: A Multidisplinary Perspective. Oxford University Press, New York, NY, pp. 411-488. (Reprinted in Wilson, D., Sperber, D., 2012, pp. 230-258.)

Wilson, D., 2011. The conceptual-procedural distinction: Past, present and future. In: Escandell-Vidal et al., pp. 3-31.

Wilson, D., Carston, R., 2007. A unitary approach to lexical pragmatics: Relevance, inference and ad hoc concepts. In: Burton-Roberts, N. (Ed.), Pragmatics. Palgrave, Basingstoke, pp. 230-259.

Wilson, D., Sperber, D., 1993. Linguistic form and relevance. Lingua 90, 1-25. (Reprinted in Wilson, D., Sperber, D., 2012, pp. 149-168.)

Wilson, D., Sperber, D., 2012. Meaning and Relevance. Cambridge University Press, Cambridge.

Wilson, D., Wharton, T., 2006. Relevance and prosody. Journal of Pragmatics 38, 1559-1579. 